\title{
DINÂMICA DA INFESTAÇÃO DE Brevipalpus phoenicis (GEIJSKES, 1939) (ACARI:TENUIPALPIDAE) EM POMARES CÍTRICOS DA BAHIA, BRASIL ${ }^{1}$
}

\author{
SUELY XAVIER DE BRITO SILVA², FRANCISCO FERRAZ LARANJEIRA ${ }^{3}$, \\ EDUARDO CHUMBINHO DE ANDRADE ${ }^{4}$, DÉCIO DE OLIVEIRA ALMEIDA ${ }^{5}$
}

RESUMO-Em duas regiões da Bahia - Litoral Norte (LN) e Recôncavo Baiano (RB) quantificaram-se a dinâmica espaço-temporal da infestação de plantas cítricas pelo ácaro Brevipalpus phoenicis. Dez pomares de cada região foram avaliados mensalmente (de abril de 2008 a fevereiro de 2011), nos quais 21 plantas tiveram três frutos/planta vistoriados com lupa de 10x para registrar a presença ou ausência do ácaro. A proporção média de plantas infestadas variou entre 0,38 e 1,0. Em frutos, a proporção mínima de infestação foi 0,10 e máxima de 0,73 no $L N$ e 0,66 no RB. O processo de infestação foi sazonal, com mais unidades infestadas na primavera-verão (Nemenyi, $\mathrm{p}<0,05$ ). A análise de densidade espectral mostrou a ocorrência de dois tipos de ciclos: um com período aproximado de 2 meses, possivelmente relacionado com a biologia do ácaro e outro anual, decorrente da interação vetor-hospedeiro-ambiente. Em ambas as regiões, a aleatoriedade caracterizou o padrão espacial da infestação do ácaro intra e interpomares. Não foram observados sintomas de leprose dos citros no RB.

Termos para indexação: vetor do VLCi, padrão espacial, sazonalidade da infestação.

\section{INFESTATION DYNAMICS OF Brevipalpus phoenicis (GEIJSKES, 1939) (ACARI:TENUIPALPIDAE) IN CITRUS ORCHARDS IN BAHIA, BRAZIL}

\begin{abstract}
The spatio-temporal dynamics of Brevipalpus phoenicis infestation was quantified in two regions of the state of Bahia, Brazil (North Coast-NC and Recôncavo Baiano-RB). In each region, 10 orchards were evaluated monthly (from April 2008 to February 2011), in which 21 plants had inspected three fruits per plant with a magnifying lens (10x) to record the presence or absence of the mite. The average proportion of infested plants varied between 0.38 and 1.0. In fruits, the minimum proportion of infestation was 0.10 and maximum, of 0.73 for $\mathrm{NC}$ and 0.66 in the RB. The infestation process had a strong seasonal component with more infested units detected in spring or summer (Nemenyi, $\mathrm{p}<0.05$ ). The spectral density analysis showed the occurrence of two cycles of infestation: one of 2 to 3 months, possibly related to the mite's biology and other larger, annual, arising from the interaction vector-host-environment. In both regions the spatial pattern of mite infestation within and between orchards was random. No symptoms of citrus leprosies were found in RB.
\end{abstract}

Index terms: CiLV vector, spatial pattern, seasonality of infestation.

\footnotetext{
'(Trabalho 199-11). Recebido em: 02-08-2011. Aceito para publicação em: 22-11-2011.

${ }^{2}$ Doutoranda em Ciências Agrárias/UFRB. Cruz das Almas/BA. Fiscal estadual Agropecuário (ADAB). E-mail: sukabrito@hotmail.com ${ }^{3}$ Doutor, Pesquisador da EMBRAPA/CNPMF. Prof. do Programa de Pós-Graduação da UFRB. Orientador. E-mail:chico@cnpmf.embrapa.br ${ }^{4}$ Doutor, Pesquisador da EMBRAPA/CNPMF. E-mail: eandrade@cnpmf.embrapa,br ${ }^{5}$ Graduando de Agronomia, UFRB. Bolsista da FAPESB. E-mail:bahiacruz2002@yahoo.com.br
} 


\section{INTRODUÇÃO}

No complexo leprose dos citros, muita atenção é dada aos ácaros do gênero Brevipalpus por serem os transmissores dessa virose não sistêmica, que afeta ramos, folhas e frutos. Segundo Childers e Rodrigues (2005), as introduções de material de propagação ou de plantas ornamentais de locais onde a leprose dos citros e demais viroses associadas aos Brevipalpus ocorrem, aumenta o risco de disseminação para novas áreas. Porém, a curtas distâncias, considerando tratar-se de uma virose não sistêmica, o vetor adquire papel relevante ao progresso espaçotemporal da doença dentro da planta e do pomar (COLARICCIO et al., 1995). Os estudos acerca dos ácaros Brevipalpus phoenicis (Geijskes, 1939) (Acari: Tenuipalpidae) habitualmente têm como cenário as paisagens citrícolas com registro de ocorrência do Vírus da Leprose dos Citros - VLCi. Esse é o caso, por exemplo, da investigação do padrão espacial do ácaro em pomares de São Paulo (BASSANEZI; LARANJEIRA, 2007), do desenvolvimento de modelos de disseminação da leprose baseados na presença do ácaro (FRANCISCON et al., 2008) e de mecanismos de dispersão de B. phoenicis (ALVES et al., 2005). Assim, considerando-se a importância socioeconômica da citricultura do $\mathrm{RB}$, a máxima prevalência do ácaro B. phoenicis naquela região (SILVA et al., 2009) e a ocorrência de leprose dos citros no parque citrícola do LN, este trabalho objetivou: em ambas as regiões baianas (RB e LN) (i) quantificar a proporção de plantas e frutos com infestação por B. phoenicis; (ii) caracterizar o padrão espacial de infestação do vetor do VLCi, e (iii) descrever a dinâmica temporal da infestação.

\section{MATERIAL E MÉTODOS}

Regiões Estudadas. Recôncavo Baiano (RB) e Litoral Norte (LN) distam entre si, aproximadamente, $100 \mathrm{~km}$. O RB é banhado pelas bacias hidrográficas dos Rios Paraguaçu e Capivari. Considerando dados meteorológicos da série temporal de 1971 a 1997, D`Angiolella et al. (2011) caracterizaram o clima do RB, como Am (classificação de Köeppen): tropical úmido monçônico, tipo que apresenta chuvas inferiores a $60,0 \mathrm{~mm}$ no mês mais seco. A região do $\mathrm{LN}$ compreende as bacias hidrográficas dos Rios Real e Itapicuru, cujo clima é do tipo seco a subúmido, com precipitação e temperatura médias em torno de $928 \mathrm{~mm} \mathrm{e} 24,1^{\circ} \mathrm{C}$, respectivamente (CEI, 1994). Incidência do Vetor. A incidência de Brevipalpus, considerada como a proporção de plantas ou frutos infestados, foi obtida a partir da observação mensal de dez pomares de cada região, no período de abril de 2008 a fevereiro de 2011. Avaliaram-se ao acaso 21 plantas por pomar, mediante caminhamento em "W". Em cada planta, avaliou-se a superfície total de três frutos com auxílio de lupa de 10x de aumento, totalizando-se 63 frutos por pomar. A presença ou ausência do ácaro era registrada de forma binária (1 ou zero, respectivamente), sem quantificar o número de ácaros encontrados ou seu estádio de desenvolvimento. Os frutos amostrados situavam-se no interior da copa das árvores, em diferentes quadrantes da planta. Cada planta foi também inspecionada visualmente para a identificação de sintomas da leprose dos citros. A metodologia adotada é a preconizada pela Produção Integrada de Frutas - Citros (PIF) para o monitoramento de ácaros (MAPA, 2004).

Para cada área, foi determinada a proporção de plantas e frutos infestados em cada avaliação (p). $\mathbf{p}=\sum \mathbf{X}_{\mathbf{i}} / \mathbf{n N}$, em que: $\sum \mathbf{X}_{\mathrm{i}}$ é o somatório do número de amostras infestadas pelo ácaro em cada unidade amostral i; $\mathbf{n}$ é o número de amostras por unidade amostral, e $\mathbf{N}$ é o número total de unidades amostrais. Análise da Dinâmica Temporal. Os dados mensais de incidência foram usados para plotar as curvas de flutuação de frutos e de plantas infestados. Os padrões cíclicos foram estudados pela análise da densidade espectral (CHATFIELD, 1985). O procedimento Trend Subtract eliminou as tendências de variação, restando apenas a tendência cíclica. As estimativas foram suavizadas pela janela Hamming de largura 5, para evitar os picos não representativos das variações temporais (LARANJEIRA, 2002). Análise Estatística. As curvas de infestação foram subdivididas em estações do ano (primavera, verão, outono e inverno). Tratando-se de dados correlacionados que não seguiam a distribuição normal, utilizou-se a análise de variância de Friedman para apontar diferenças sazonais na infestação. Para a separação de médias, lançou-se mão do teste de Nemenyi $(\mathrm{p}<0,05)$, versão não paramétrica do teste de Tukey (ZAR, 1996). Como o número de observações para cada estação do ano e região não era igual, para cada estação do ano, as observações foram selecionadas aleatoriamente, oito para o RB e sete para o LN. Análise do Arranjo Espacial. Os padrões espaciais da infestação foram determinados por metodologia descrita por Madden e Hughes (1995). Os padrões espaciais foram determinados a partir do Índice de Dispersão (ID), o qual é baseado na relação entre a variância observada e a variância binomial do processo em estudo, através da equação:

ID $=$ Vobs $/$ Vbin, sendo: Vobs $=\sum(\mathrm{Xi}-\mathrm{n} \mathrm{p})^{2}$ $/ \mathrm{n}^{2}(\mathrm{~N}-1)$, em que: $\sum \mathbf{X i}$ é o somatório do número de componentes infestados (plantas ou frutos) em cada 
unidade amostral $\mathbf{i}$, e $\mathbf{N}$ é o número total de unidades amostrais em cada avaliação. Vbin $=p(1-p) / n$, em que: $\mathbf{p}$ é a incidência média na área amostrada, e $\mathbf{n}$ é o número de componentes avaliados por amostra. A hipótese nula foi a de que o padrão observado era aleatório. Valores de ID estatisticamente iguais a 1 foram considerados indicativos de padrão aleatório (Teste $\chi^{2}, \mathrm{P}<0,05$ ), enquanto valores estatisticamente superiores a 1 se constituíram como indicativos de agregação dos dados e valores inferiores a 1, indicativos de uniformidade.

\section{RESULTADOS E DISCUSSÃO}

Dinâmica temporal da infestação. Não foram observadas tendências generalizadas a aumento ou diminuição na infestação ao longo do tempo, em qualquer das regiões. As curvas de infestação apresentaram-se cíclicas no RB e no LN, tanto para plantas quanto para frutos (Figura 1). De maneira geral, os picos ocorreram em meses de primavera ou verão, com valores nunca inferiores a 0,9 para plantas e 0,65 para frutos. As menores proporções de plantas ou frutos infestados foram registradas em meses de outono ou inverno, com valores mínimos de 0,38 para plantas e 0,15 para frutos. Os valores medianos de infestação nas duas regiões foram muito semelhantes, tanto para plantas (LN: 0,81; RB: 0,79) quanto para frutos (LN: 0,40; RB: 0,39). As proporções elevadas tanto de frutos quanto de plantas infestadas, o padrão cíclico e a ausência de aumento ou diminuição consistente ao longo do tempo, indicam que o vetor da leprose é endêmico nas duas regiões. O reduzido uso de agrotóxicos em geral poderia explicar tal situação. Mesmo no LN, onde a leprose já foi registrada, não é comum o uso sistemático de acaricidas. Outro fator importante para a infestação do ácaro é a baixa variação na composição varietal dos plantios. A quase totalidade dos pomares é de laranja Pera (Citrus sinensis L. Osbeck). Trindade e Chiavegato (1990) mostraram que as variedades Natal, Valência e Pera-Rio foram mais favoráveis ao acarino do que as variedades Ponkan, Limão-Cravo, LaranjaAzeda e Cleópatra. Ainda que sejam ecossistemas distintos, o RB e LN apresentam condições bióticas e abióticas favoráveis à constância do ácaro vetor do VLCi. Em ambas as regiões, há diversificada paisagem agrícola, sendo comuns os cultivos intercalares (milho, feijão, fava, amendoim, mandioca, abóbora e maracujá). Não raro, o único agrotóxico utilizado é o formicida e, para o controle da vegetação infestante, faz-se capina manual. Essas características podem atuar de diferentes modos na dinâmica populacional deste ácaro. Brevipalpus é um ácaro polífago e com diversidade vegetal, e ele teria alternativas alimen- tares que não os citros, caso a cultura principal não proveja condições adequadas ao seu ciclo de vida. A análise de densidade espectral revelou a existência de ciclos bem definidos de infestação. No RB, foram observados dois ciclos principais, um com período aproximado de 2,2 meses e outro ao redor de 11 meses, tanto para infestação em plantas quanto em frutos (Figuras 2A e 2C). No LN, o ciclo mais intenso teve período de seis meses, enquanto o secundário variou entre 2 e 3 meses, conforme a infestação era em plantas ou em frutos (Figuras 2B e 2D). O ciclo de maior período parece refletir a influência de fatores mais complexos, tais como variáveis climáticas (MORAES; FLECHTMANN, 2008). Possivelmente, temperatura e umidade influenciaram na dinâmica populacional do ácaro vetor do VLCi no $\mathrm{LN}$, tendo em vista os picos populacionais terem ocorrido na primavera e no verão, habitualmente, de menor umidade relativa e maior temperatura. De maneira complementar, as menores proporções de plantas infestadas foram registradas no outono e no inverno, período no qual, frequentemente, são registrados os maiores índices de umidade e os menores de temperatura. O ciclo de curta duração parece ter relação com o ciclo de vida do ácaro. Seu período, de dois a três meses, coincide com as estimativas de Haramoto (1966), o qual avaliou a biologia do ácaro em mamoeiro. Nas temperaturas de 20 e $25^{\circ} \mathrm{C}$ e umidade relativa de 65 a $70 \%$, o período de ovo-adulto foi de aproximadamente 49 e 29 dias, enquanto o de longevidade foi de 46 e 35 dias, respectivamente. Ou seja, o ciclo de vida variando entre 64 e 95 dias, período correspondente ao menor ciclo detectado pela curva de densidade espectral. Sazonalidade. A análise de Friedman indicou diferença significativa entre estações do ano para ambas as regiões e tipos de infestação (plantas ou frutos, Figura 3). O padrão sazonal foi similar para infestação em plantas, em ambas as regiões: altas infestações na primavera e no verão, com tendência a redução no outono e no inverno (Figuras 3A e 3B). Os valores registrados no verão não diferiram significativamente dos da primavera pelo teste Nemenyi $(\mathrm{P}<0,05)$. Em todas as situações, os valores do outono não puderam ser distinguidos significativamente dos do inverno. As altas infestações nos meses mais quentes e secos, em contraste com as baixas infestações no outonoinverno, além de apontarem para relações com o clima, servem como subsídio para ações da defesa fitossanitária. Em conjunto com a caracterização do padrão espacial, os dados de proporção de frutos e plantas infestados servem para o detalhamento de planos de amostragem. No RB, área livre da leprose, estratégias para a manutenção desse status podem ser aplicadas, tais como: coletas periódicas de ácaros adultos para a detecção precoce do vírus (KUBO et al., 2011), antes da ocorrência de sintomas. No LN, 
os planos de amostragem podem guiar ações de redução de inóculo, seja por aplicação de acaricidas, seja por remoção de partes afetadas das plantas. Dinâmica espacial da infestação. O ID intrapomares variou intensamente ao longo do tempo, sem, no entanto, ultrapassar os limites da aleatoriedade (Figuras 4A e 4C). Na única vez em que isso ocorreu (maio de 2010, Figura 4A), a média do ID ficou pouco abaixo do limite indicativo de uniformidade. A maioria das avaliações resultou em valores de ID interpomares indistinguíveis de 1, em ambas as regiões (Figuras 4B e 4D). Picos ocasionais de agregação foram observados, mas nenhum tipo de ciclo foi detectado. Assim, o padrão espacial da infestação por Brevipalpus em pomares da Bahia pode ser caracterizado como aleatório, coincidindo com estudos realizados na Colômbia (SOLANO et al., 2008). Essa informação poderá ser utilizada como subsídio de revisões nos índices amostrais, pois, segundo Wilson e Room (1983), o tipo de agregação de um organismo influi no número de unidades amostrais necessário para estimar a densidade de uma população. Atualmente, objetivando ao controle do vetor em áreas de ocorrência do VLCi , o índice amostral é 1\% das plantas do pomar. Caso $10 \%$ dessas plantas estejam infestadas, toma-se a decisão de controle (GRAVENA, 2004). Afirma Southwood (1978) que, para a construção de um plano de amostragem, devem ser considerados aspectos ligados à biologia, comportamento, distribuição espacial, número e tamanho da amostra, bem como fatores econômicos. Assim, uma revisão dos índices vigentes se justificaria. Não foram encontrados estudos similares para plantios citrícolas do Nordeste. Além disso, pelo fato de ter sido conduzido em condições de campo, o presente estudo pode agregar informações a programas de desenvolvimento da citricultura, os quais primem por desenvolvimento sustentável desta cadeia produtiva. Diante dos elevados índices de infestação e da constância do ácaro nos pomares, algumas estratégias de defesa fitossanitária poderiam ser implantadas para manutenção de áreas livres: (i) para a comercialização in natura de frutos procedentes de áreas de ocorrência de VLCi, tornar obrigatória a lavagem de frutos em packing house; (ii) estabelecer rotas de risco de disseminação da praga; (iii) intensificar a fiscalização do trânsito doméstico de vegetais; (iv) avaliar o impacto econômico futuro do RB, num cenário de invasão da leprose dos citros, e (v) qualificar a mão de obra rural acerca da sintomatologia e danos associados à doença.

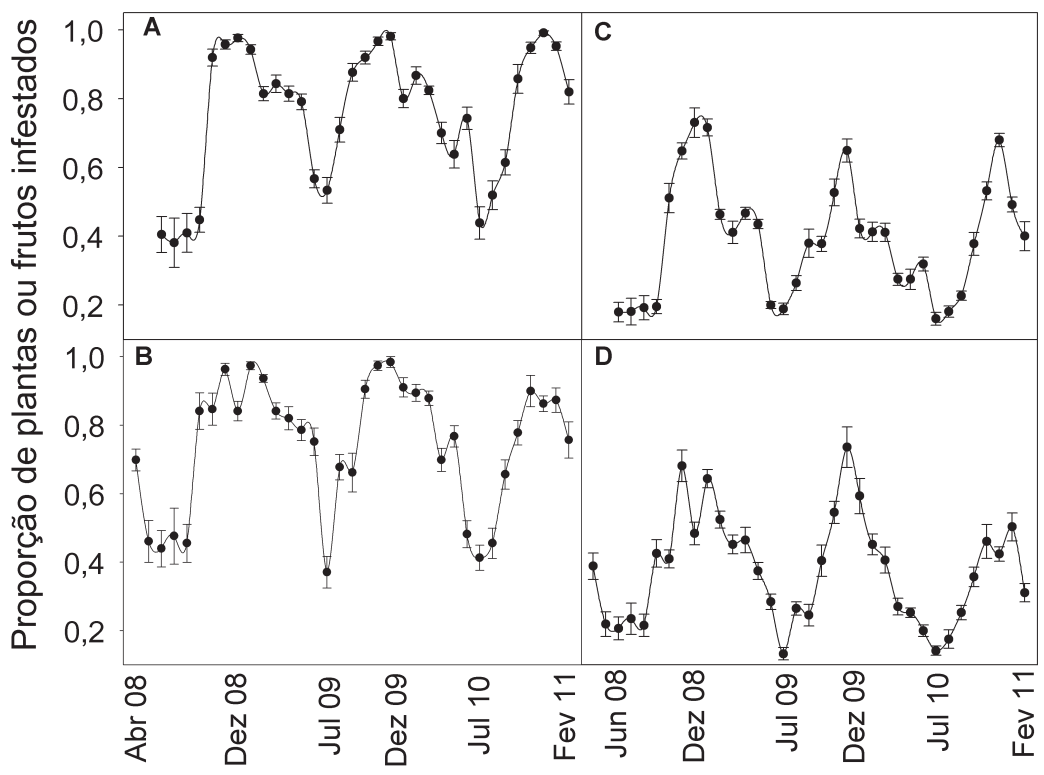

Mês

FIGURA 1 - Variação mensal na proporção de plantas ou frutos infestados por Brevipalpus phoenicis em duas regiões citrícolas da Bahia, Recôncavo Baiano (A, plantas; C, frutos) e Litoral Norte (B, plantas; D, frutos). Pontos pretos representam as médias de dez pomares (21 plantas e 63 frutos amostrados); a barra representa o erro-padrão da média. 


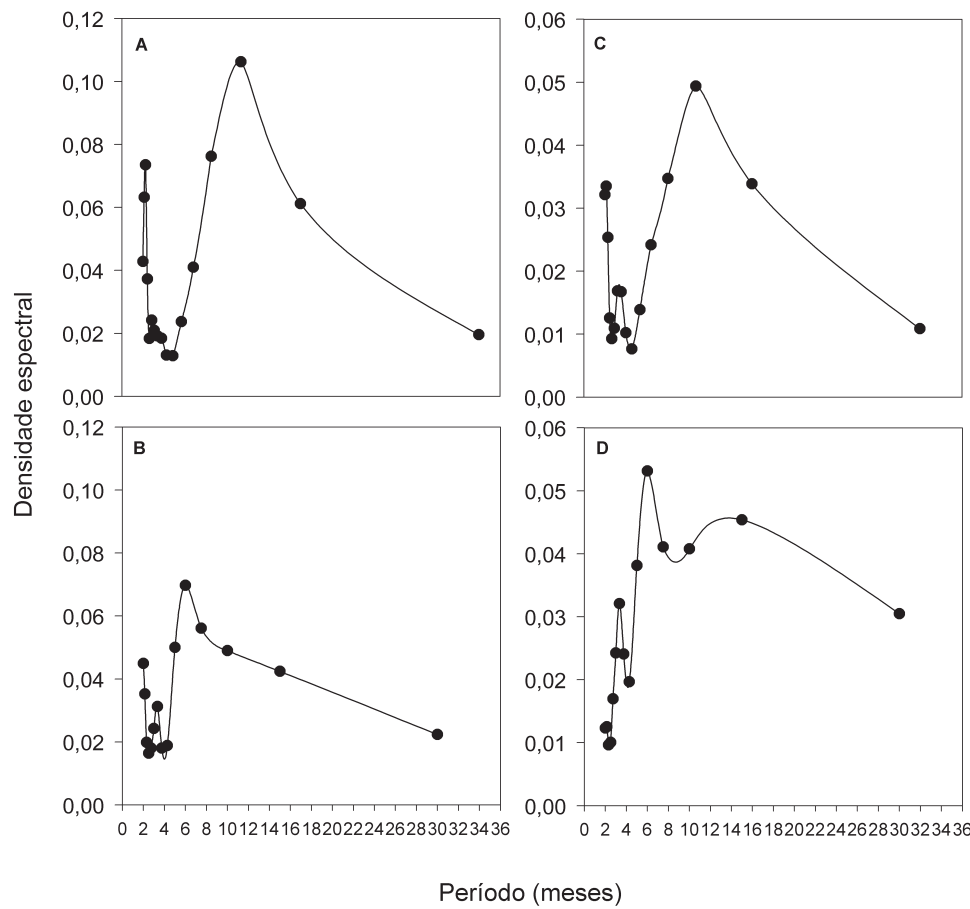

FIGURA 2 - Densidade espectral associada às curvas médias de infestação por Brevipalpus phoenicis em duas regiões citrícolas da Bahia, Recôncavo Baiano (A, plantas; C, frutos) e Litoral Norte (B, plantas; D, frutos). Picos de densidade espectral indicam o período de repetição dos ciclos que compõem a flutuação das infestações.
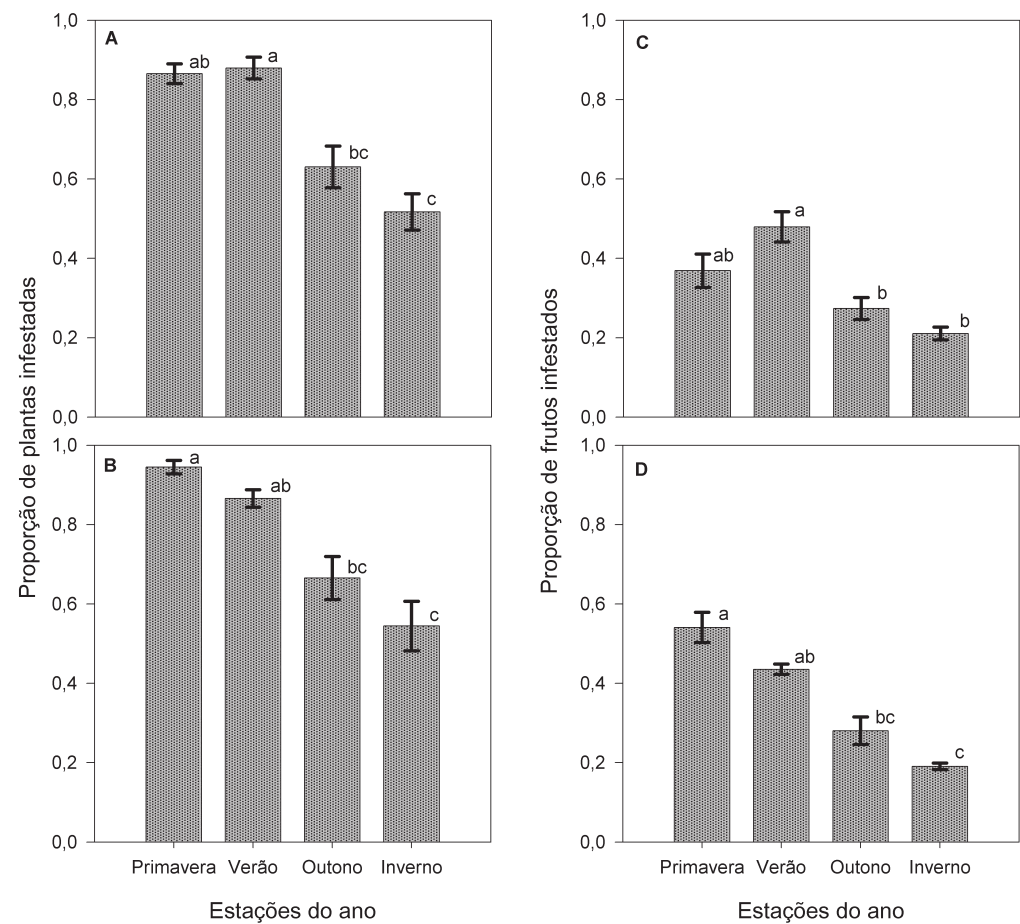

FIGURA 3 - Sazonalidade da infestação por Brevipalpus phoenicis em duas regiões citrícolas da Bahia, Recôncavo Baiano (A, plantas; C, frutos) e Litoral Norte (B, plantas; D, frutos). As barras representam as médias da proporção de plantas ou frutos infestados em dez pomares (21 plantas e 63 frutos amostrados); a barra representa o erro-padrão da média. Barras com letras minúsculas iguais não diferem significativamente pelo teste não paramétrico de Nemenyi $(\mathrm{P}<0,05)$. 


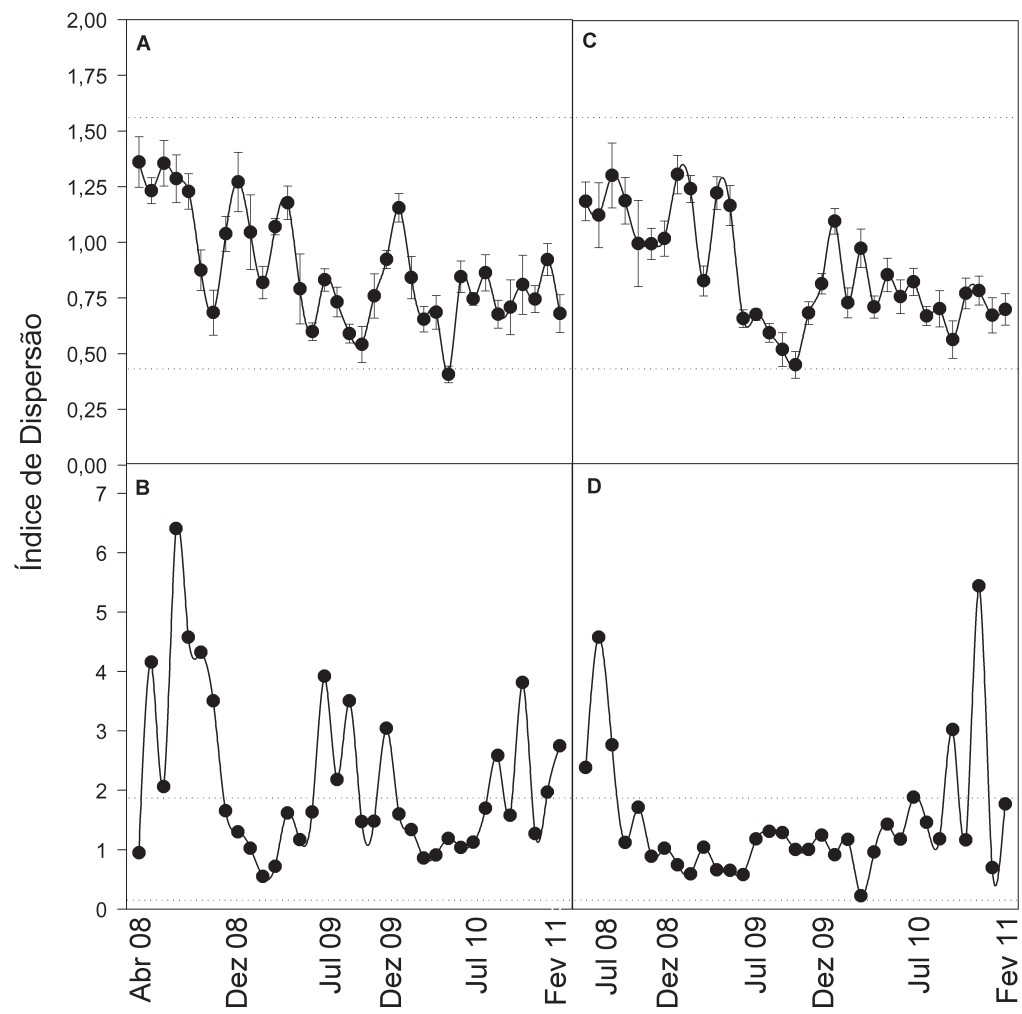

Mês

FIGURA 4 - Variação mensal nos índices de dispersão da infestação de Brevipalpus phoenicis em duas regiões citrícolas da Bahia, Recôncavo Baiano (A, intrapomares; B, interpomares) e Litoral Norte (C, intrapomares; D, interpomares). Para a dispersão intrapomares, os pontos pretos representam as médias de dez pomares (21 plantas e 63 frutos amostrados); a barra representa o erro-padrão da média. A dispersão interpomares não apresenta variação. Valores entre as linhas pontilhadas indicam aleatoriedade; abaixo da linha pontilhada inferior indicam uniformidade e, acima da linha pontilhada superior de cada gráfico, indicam agregação estaticamente significativa.

\section{CONCLUSÕES}

1-A infestação de ácaros Brevipalpus, além de alta nas regiões estudadas, com proporções medianas de plantas infestadas superiores a 0,78 , apresenta ciclos de curta e longa duração, com expressiva sazonalidade.

2-Maiores infestações de B. phoenicis ocorrem na primavera, e as menores, no inverno. Apesar de o vetor ser prevalente na região, não foram encontrados sintomas de leprose dos citros nos pomares avaliados do Recôncavo Baiano e Litoral Norte, caracterizando-os como locais livres da praga.

3-A dinâmica espacial da infestação não apresentou ciclos definidos, sendo caracterizada pela aleatoriedade, tanto entre pomares quanto entre plantas de um mesmo pomar.

\section{REFERÊNCIAS}

ALVES, E. B.; CASARIN, N. F. B.; OMOTO, C. Mecanismos de Dispersão de Brevipalpus phoenicis (Geijskes) (Acari: Tenuipalpidae) em Pomares de Citros. Neotropical Entomology, Londrina, v.34, p.89-96, 2005.

BASSANEZI, R. B.; LARANJEIRA, F. F. Spatial patterns of leprosis and its mite vector in commercial citrus groves in Brazil. Plant Pathology, Oxford, v.56, p.97-106, 2007.

CEI - Centro de Estatística e Informações. Informações básicas dos municípios baianos: região nordeste. Salvador, 1994. v.11, 495p. 
CHATFIELD, C. The analysis of time series: an introduction. $3^{\text {rd }}$ ed. New York: Chapman e Hall, 1985. 286p.

CHILDERS, C. C.; RODRIGUES, J. C. V. Notes on Acari species on ornamental plants from Central America imported for propagation in Florida and potential risks of exotic pest introductions. Florida Entomologist, Gainsville, v.88, p.408-414, 2005.

COLARICCIO, A.; LAVISSOLO, O.; CHAGAS, C. M.; GALLETI, S. R.; ROSSETTI, V.; KITAJIMA, E. W. Mechanical transmission and ultrastructural aspects of citrus leprosis virus. Fitopatologia Brasileira, Brasília, v.20, p.208-213, 1995.

D`ANGiOLELlA, G. L. B.; CASTRO NETO, M. T.; COELHO, E. F. Caracterização climática dos tabuleiros costeiros do recôncavo baiano. Disponível em: <http://www.cbmet.com/cbm-files/13831e6409241d28220970befb518cd63d.pdf $>$. Acesso em: 12 jun. 2011.

FRANCISCON, L.; RIBEIRO JUNIOR, P. J.; KRAINSKI, E. T.; BASSANEZI, R. B.; CZERMAINSKI, A. B. C. Modelo autologístico espaçotemporal com aplicação à análise de padrões espaciais da leprose-dos-citros. Pesquisa Agropecuária Brasileira, Brasília, v.43, n.12, p.1677-1682, 2008.

GRAVENA, S. Manejo integrado de doenças é vital na produção de citros. Visão Agrícola, Piracicaba, n.2, p.54-59, 2004.

HARAMOTO, F. H. Biology and control of Brevipalpus phoenicis (Geijskes) (Acarina:Tenuipalpidae). 1966. $101 \mathrm{f}$. Thesis (Doctor in Philosophy in Entomology) -University of Hawaii, Honolulu, 1966

KUBO, K. S.; NOVELLI, V. M.; BASTIANEL, M.; LOCALI-FABRIS, E. C.; ANTONIOLI-LUIZON, R.; MACHADO, M. A.; FEITAS-ASTÚA, J. Detection of Brevipalpus - transmitted viruses in their mite vectors by RT-PCR. Experimental and Applied Acarology, Amsterdam, v.54, p.33-39, 2011.

LARANJEIRA, F. F. Epidemiologia da clorose variegada dos citros no Estado de São Paulo. 2002. 158 f. Tese (Doutorado em Fitopatologia) - Escola Superior de Agricultura “Luiz de Queiroz", Universidade de São Paulo, Piracicaba-SP, 2002.
MAPA. Instrução Normativa SARC/MAPA 006, 6 setembro de 2004. Normas técnicas específicas para a produção integrada dos citros. Diário Oficial da União,10 set. 2004.

MADDEN, L. V. Dynamic nature of within-field disease and pathogens distributions. In: JEGER, M. J. (Ed.). Spatial components of plant disease epidemics. New Jersey: Prentice-Hall, 1989. cap. 5, p.159-176.

MADDEN, L. V.; HUGHES, G. Plant disease incidence: distributions, heterogeneity and temporal analysis. Annual Review Phytopathology, Palo Alto, v. 33, p. 529-564, 1995.

MORAES, G. J.; FLECHTMANN, C. H. W. Manual de acarologia: acarologia básica e ácaros de plantas cultivadas no Brasil. Ribeirão Preto: Holos, 2008. 308p.

SILVA, S. X. B.; SOARES, A. C. F.; LARANJEIRA, F. F.; ALMEIDA, D. O. Amostragem piloto e incidência do ácaro vetor do CiLV em pomares de cítricos do Recôncavo Baiano.. Tropical Plant Pathology, Brasília, v.34, p.125, 2009. Suplemento

SOLANO, D. A.; ÁLVAREZ-HERRERA, J. G.; RODRIGUEZ, J. A. Distribución espacial de Brevipalpus phoenicis, vector de la leprosis de los cítricos en el cultivo de naranja Valencia (Citrus sinensis) en Yopal, Casanare (Colombia). Agronomía Colombiana, Bogotá, v.26, n.3, 2008.

SOUTHWOOD, T. R. E. Ecological methods, with particular reference to the study of insect populations. 2. ed. New York: John Wiley e Sons, 1978. 525p.

TRINDADE, L. F.; CHIAVEGATO, L. G. Colonização por Brevipalpus obovatus Donnadieu, 1875, Brevipalpus californicus (Banks, 1904) e Brevipalpus phoenicis (Geijskes, 1939) (Acari; Tenuipalpidae) em variedades cítricas. Laranja, Cordeirópolis, v.11, n.1, p.227-270, 1990.

WILSON, L. T.; ROOM, P. M. Clumping patterns of fruit and arthropods in cotton with implications for binomial sampling. Envinronmental Entomology, Lanham, v.12, n.3, p.50-58, 1983.

ZAR, J. H. Biostatistical analysis. 3. ed. New Jersey: Prentice Hall, 1996. 865p. 